Article

\title{
Slotted Blades Savonius Wind Turbine Analysis by CFD
}

\author{
Andrea Alaimo $^{1, *}$, Antonio Esposito ${ }^{1}$, Alberto Milazzo ${ }^{2}$, Calogero Orlando ${ }^{1}$ \\ and Flavio Trentacosti ${ }^{1}$
}

${ }^{1}$ Faculty of Engineering and Architecture, Kore University of Enna, Cittadella Universitaria, 94100 Enna, Italy

${ }^{2}$ Faculty of Engineering, University of Palermo, Viale delle Scienze, 90128 Palermo, Italy

* Author to whom correspondence should be addressed; E-Mail: andrea.alaimo@unikore.it; Tel.: +39-0935-536490.

Received: 13 November 2013; in revised form: 27 November 2013 / Accepted: 28 November 2013 / Published: 4 December 2013

\begin{abstract}
In this paper a new bucket configuration for a Savonius wind generator is proposed. Numerical analyses are performed to estimate the performances of the proposed configuration by means of the commercial code COMSOL Multiphysics ${ }^{\circledR}$ with respect to Savonius wind turbine with overlap only. Parametric analyses are performed, for a fixed overlap ratio, by varying the slot position; the results show that for slot positioned near the blade root, the Savonius rotor improves performances at low tip speed ratio, evidencing a better starting torque. This circumstance is confirmed by static analyses performed on the slotted blades in order to investigate the starting characteristic of the proposed Savonius wind generator configuration.
\end{abstract}

Keywords: wind turbine; Savonius; CFD analysis; slotted blades

\section{Introduction}

The International Energy Agency expects that by 2030 the primary world energy demand will increase by $45 \%$, and hydrocarbon fuels will continue to have a primary role, covering $80 \%$ of the demand [1]. The increase of the world energy demand, mainly fulfilled by hydrocarbon fuels, has resulted in an increment in greenhouse gas emissions, with serious repercussions on our environment. Reduction in greenhouse gas emissions can be achieved by increasing plant energy efficiency and by taking concrete actions on energy saving and recovery in the industrial and civil field [2-4]. Although wind energy is 
able to replace traditional energy sources in clean ways, many concerns are associated with its use in urban environments, such as performances in urban environment or noise level, as well as the visual impact, concerning integration with existing buildings [5]. The vertical axis wind turbines of Savonius and Darrieus types are the most interesting ones from the feasibility and sustainability point of view in the urban environment. Efficiency of Savonius generators is rather low compared to both horizontal axis and Darrieus type turbines [6]; however, they show some advantages relating to: (i) simple and inexpensive design; (ii) self-activation in presence of wind; (iii) operating capability not reliant on wind direction. Moreover, they are characterized by high starting torque, which represents an advantage for urban applications. There are many studies in the literature focusing on improvement of aerodynamic performance of Savonius turbine. Among these, several authors have analyzed savonius blade behavior in the presence of valves, or gaps, in the center area of the blades, in order to allow the flow passing from one side of blade to another and thus reducing the drug for the retreating blade. Plourde et al. [7] and Abraham et al. [8] have analyzed experimentally the behavior of both the end plates and the effects of longitudinal vents aligned with the axis of rotation. Results have shown that use of venting give less improvements of the blade performances if compared to endplate. Saha et al. [9] have investigated the performances of two-stage rotor system by inserting a valves on the concave side of blade able to be opened in the advancing blade and closed in the returning one. This configuration has allowed to reduce the negative torque of the rotor considerably. Gupta et al. [10] have investigated the behavior of a combined Savonius-Darrieus wind rotor and the associated advantages while Altan et al. [11] designed a deflector with different arrangements placed in front of the rotor with the aim of preventing the negative torque. Fujisawa [12] showed that in order to increase the power coefficient of the Savonius generator it is useful to superimpose blades close to the rotational axis. Recently, a systematic study on the behavior of Savonius wind turbine with blades overlapping was performed by Akwa et al. [13], who found that the best performance can be obtained for a particular overlapping ratio. On this basis, this paper presents a new slotted bucket configuration numerically analyzed by means of the commercial code COMSOL Multiphysics ${ }^{\circledR}$. 2-Dimensional CFD analyses are performed for both static conditions, in order to characterize the starting performance of the new configuration proposed, and dynamic conditions by varying some geometric characteristics of the slotted blades as well as the tip speed ratio. Although 3-Dimensional studies may provide a more realistic behavior of the Savonius turbine, the 2-D numerical analysis, firstly validated by means of experimental results obtained by Blackwell et al. [14], has allowed to point out the effect of the modified blade with less computational efforts.

\section{Computational Fluid Dynamic Analyses}

In this section the main geometrical features of the slotted blades are firstly defined and described in comparison with the classical Savonius wind generator [15]. Then control volumes and corresponding boundary conditions considered for the analyses are introduced and a brief description of the mathematical model used for CFD analyses are recalled for the sake of completeness. 


\subsection{Characteristics of the Slotted Blade}

The tested configurations are characterized by an overall diameter of the blade $\mathrm{Dr}=1 \mathrm{~m}$, which has been chosen in agreement with experimental and computational data [14].

Sketches of the studied Savonius blades are shown in Figure 1, where quantities used to define the overlap s/c and the slot position $\mathrm{f}$ are put in evidence. The standard Savonius turbine, which will be referred to as Standard in the remainder of the paper, see Figure 1a, is used as benchmark to assess the soundness of the proposed Slotted Blades configuration, see Figure 1b. In particular, the latter is obtained by truncating and rotating the inner part of the blade by an angle $\beta$ in the opposite direction to the turbine rotation.

Figure 1. Savonius geometry with buckets (a) overlapping; and (b) slotted blades.

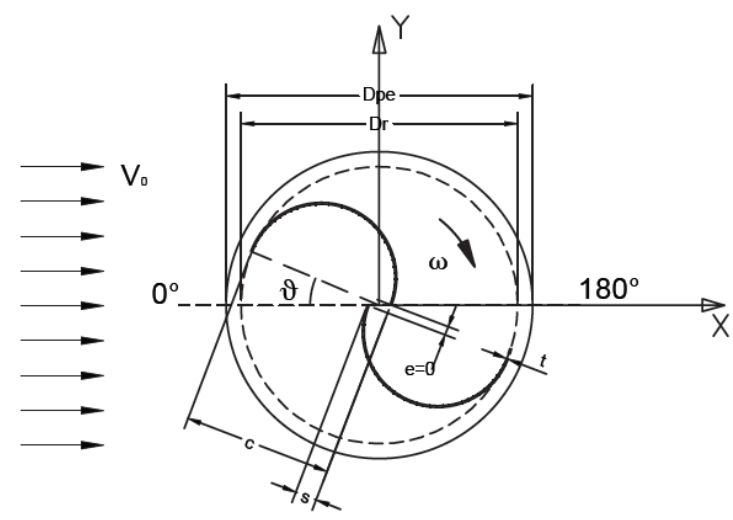

(a)

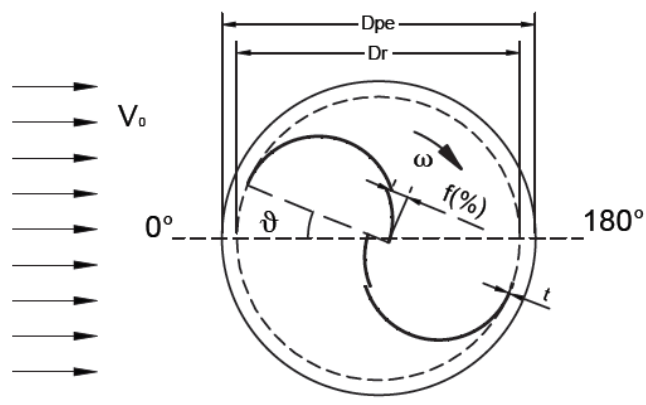

(b)

\subsection{Geometrical Characteristics of Control Volumes and Boundary Conditions}

The length of control volume along the free-stream direction is $L_{x}=60 \times$ Dr, while its width is $L_{y}=44 \times$ Dr. Inside the control volume a circular rotating domain, having diameter $D_{P E}=1.18 \times \mathrm{Dr}$, has been defined with the aim of modeling flow rotation induced by Savonius buckets as shown in Figure 2.

Figure 2. Geometry of the control volume.

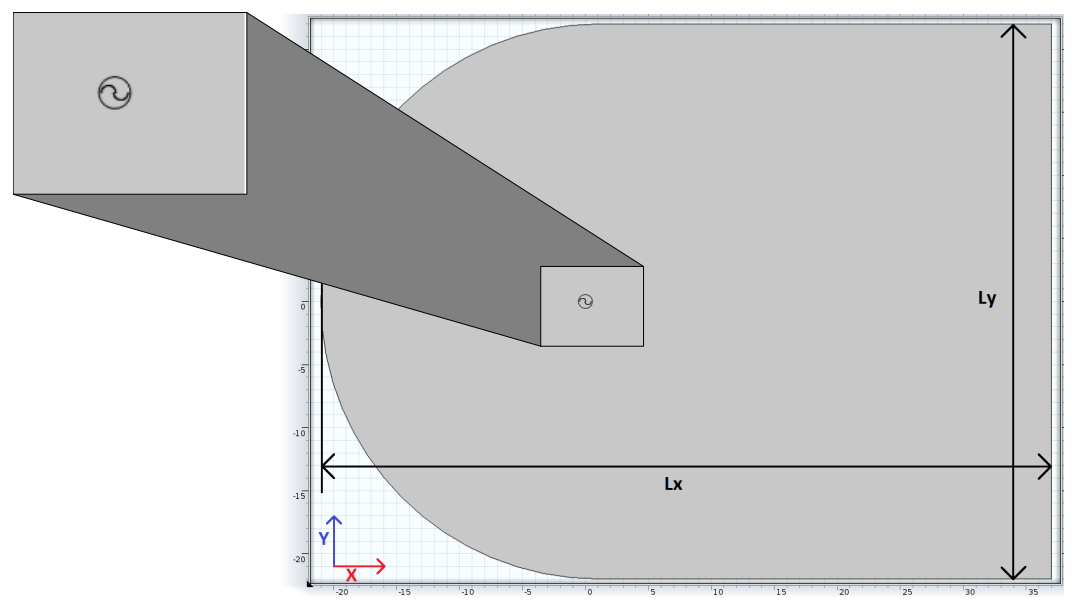


As initial boundary conditions an inlet input fluid velocity $V_{0}=7 \mathrm{~m} / \mathrm{s}$ is imposed, in order to be in accordance with the experiments carried out by [14], and has been kept constant throughout all of the simulations performed. Turbulence intensity of $I_{T}=0.1 \%$ and a length scale $L_{T}=0.01 \mathrm{~m}$ [16] are considered. Outlet conditions are represented by constant pressure equal to $P_{0}=101,325 \mathrm{~Pa}$. At the interface between the two domains flow continuity boundary condition is imposed. The free stream velocity is such that the problem is characterized by a Reynolds number $R e=4.3 \times 10^{5}$ based on rotor diameter length.

\subsection{Mathematical Model}

The mathematical model used to analyze the problem is based on the Navier-Stokes equations, which in their most general form read [17]:

$$
\begin{gathered}
\frac{\partial \rho}{\partial t}+\nabla \cdot(\rho \mathbf{u})=0 \\
\rho \frac{\partial \mathbf{u}}{\partial t}+\rho(\mathbf{u} \cdot \nabla) \mathbf{u}=\nabla \cdot[-p \mathbf{I}+\tau]+\mathbf{F} \\
\rho C_{p}\left(\frac{\partial T}{\partial t}+(\mathbf{u} \cdot \nabla) T\right)=-(\nabla \cdot \mathbf{q})+\tau: \mathbf{S}-\left.\frac{T}{\rho} \frac{\partial \rho}{\partial T}\right|_{p}\left(\frac{\partial p}{\partial t}+(\mathbf{u} \cdot \nabla) p\right)+Q
\end{gathered}
$$

where $\rho$ is the air density; $\mathbf{u}$ is the velocity vector; $p$ is pressure; $\tau$ is the viscous stress tensor; $\mathbf{F}$ is the volume force vector; $C_{p}$ is the specific heat capacity at constant pressure; $T$ is the absolute temperature; $t$ is the time variable; $I$ is the identity matrix; $q$ is the heat flux vector; $Q$ contains the heat sources; and $\mathrm{S}$ is the strain-rate tensor that writes as:

$$
\mathbf{S}=\frac{1}{2}\left(\nabla \mathbf{u}+(\nabla \mathbf{u})^{T}\right)
$$

Moreover the colon operator " : " denotes the double dot product of two tensors which results in a scalar defined as [18]:

$$
a: b=\sum_{n} \sum_{m} a_{n m} b_{n m}
$$

In order to close the system of Equations (1)-(3), some constitutive relationships are needed. In particular here the assumption of Newtonian fluid is considered. The viscous stress tensor becomes:

$$
\tau=2 \mu \mathbf{S}-\frac{2}{3} \mu(\nabla \cdot \mathbf{u}) \mathbf{I}
$$

where $\mu$ is dynamic viscosity. The Equations (1) and (2) formulated in a rotating coordinate system reads $[19,20]$ :

$$
\begin{gathered}
\frac{\partial \rho}{\partial t}+\nabla \cdot(\rho \mathbf{v})=0 \\
\rho \frac{\partial \mathbf{v}}{\partial t}+\rho(\mathbf{v} \cdot \nabla) \mathbf{v}+2 \rho \boldsymbol{\Omega} \times \mathbf{v}=\nabla \cdot[-p \mathbf{I}+\tau]+\mathbf{F}-\rho\left(\frac{\partial \boldsymbol{\Omega}}{\partial t} \times \mathbf{r}+\boldsymbol{\Omega} \times(\boldsymbol{\Omega} \times \mathbf{r})\right)
\end{gathered}
$$

where $\mathbf{v}$ is the velocity vector in rotating coordinate system; $\mathbf{r}$ is the position vector; and $\Omega$ is the angular velocity vector. The relation between $\mathbf{v}$ and the velocity vector in stationary coordinate system is:

$$
\mathbf{u}=\mathbf{v}+\frac{\partial \mathbf{r}}{\partial t}
$$


Thus, by means of Equation (9), the Equations (7) and (8) can be reformulated in terms of a non-rotating coordinate system and consequently solved in terms of $\mathbf{u}$. This is achieved by invoking the Arbitrary Lagrangian-Eulerian formulation [18,21]. Equations are solved in a Reynolds Average Navier-Stokes (RANS) approach where all instantaneous thermo-fluidynamical quantities are decomposed in their mean value and their fluctuating component. This approach allows us to diminish the huge amount of degrees of freedom required by the complete system of Navier-Stokes equations and consequently to cut down the computational time. The RANS equations are characterized by turbulent viscosity which changes both in time and in space and are described, for instance, by of the $k-\epsilon$ or the $k-\omega$ formulations. It is well known that such turbulent models introduce additional transport equations for the new dependent variables: the turbulent kinetic energy, $\mathrm{k}$, the dissipation rate of turbulent energy, $\epsilon$ and $\omega$ know as specific dissipation rate [22]. Model constants take the standard values proposed by Launder and Spalding [23]. The commercial available code COMSOL Multiphysics ${ }^{\circledR}$ is used to perform numerical integration of the problem governing equations. More particularly, to perform the static analysis a stationary nonlinear solver, which uses an affine invariant form of the damped Newton method as described in [24], has been used. On the other hand, the IDA solver [25] which uses variable-order variable-step-size backward differentiation formula (BDF), has been employed to carry out the dynamic analyses convergence criteria as been adequately set according to [18,24,25].

\section{Mesh Characteristics}

Considering that fixed and rotating control volumes are needed to model the problem, two different meshes are defined as follows: (i) for fixed control volume, that represents the area outside the Savonius rotor, Figure $3 \mathrm{a}$, mesh is characterized by maximum and minimum element sizes equals to $3.8 \mathrm{~m}$ and $0.01 \mathrm{~m}$, respectively. Moreover, the grow rate is fixed to 1.2; (ii) for rotating control volume, represented in Figure 3b, a moving mesh is considered. It is characterized by length of the largest element equals to $0.01 \mathrm{~m}$ while the smallest one has $0.001 \mathrm{~m}$ size.

Figure 3. Mesh characteristics of the (a) fixed domain; and (b) rotating domain.

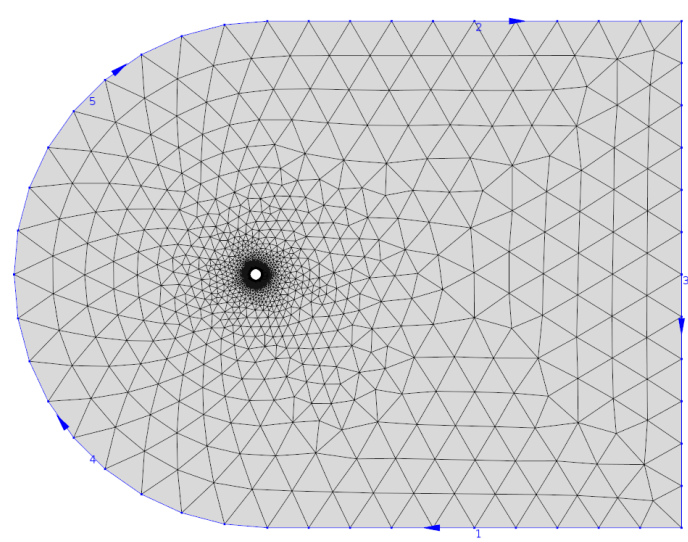

(a)

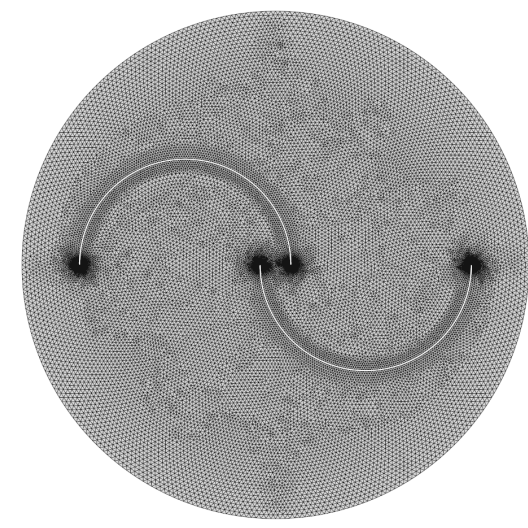

(b)

Moreover, elements at the interface between the different control volumes are chosen in order to have same characteristic size that is maintained constant along all the interface boundary. Summarizing, 
the overall number of elements is 59,600 with 1380 interface boundary elements. On the other end a structured mesh out of the rotating domain has also been considered. It consists of 69,100 elements with 2210 edge elements and is shown in Figure 4.

Figure 4. Structured mesh characteristics.

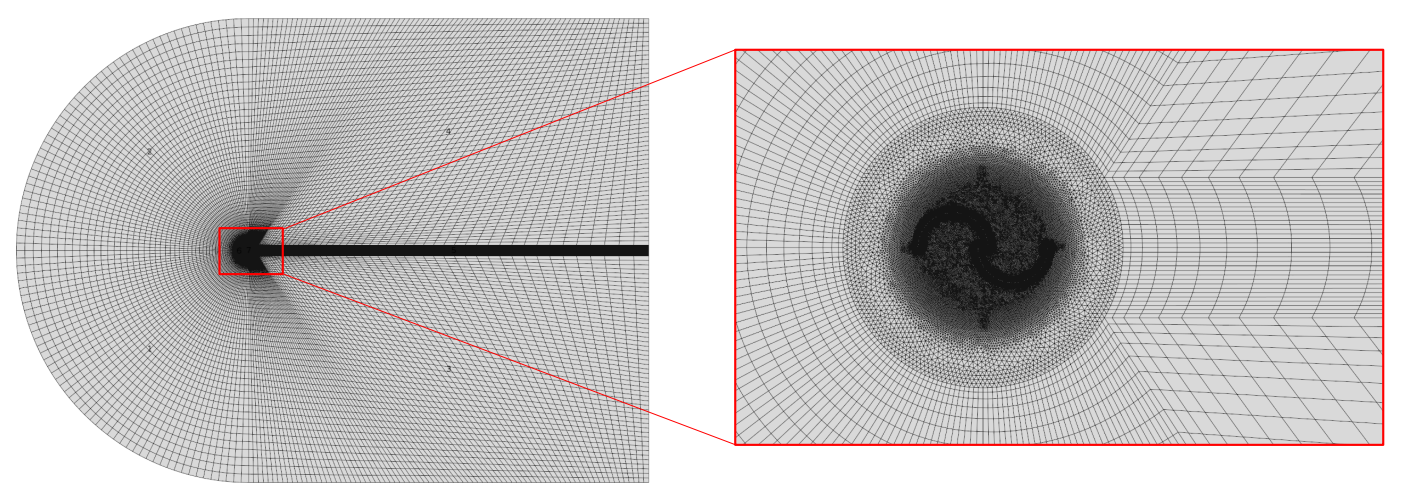

\subsection{Turbulence Models vs. Mesh Configurations}

In this section convergence analyses are performed by taking into account both turbulence models and mesh configurations. With regard to turbulence, it is known that each model has its own advantages and drawbacks. The Spalart-Allmaras $(S A)$ [26] model is a one-equation turbulence model where the near wall gradients of the transported variable are much smaller than the turbulent kinetic energy equation based $\kappa-\epsilon$ models. The standard $\kappa-\epsilon$ model [23] is more suitable when flow is fully turbulent and has given better results than SA model for turbine analysis [27]. Howell observed [28] that $2 D$ simulation has over predicted the rotor performances, whereas $3 D$ simulations have shown more accurate predictions, as also pointed out by [29]. The shear stress transport (SST) $\kappa-\omega$ turbulence model is a two-equation eddy viscosity model combining the advantages of both $\kappa-\epsilon$ formulation for free stream flow and $\kappa-\omega$ formulations in the rotor boundary layer [30]. Using this model in CFX12.0 software, Abraham et al. [8] have carried out a two-dimensional study on the Savonius rotors. Although there seems to be a general agreement between computational and experimental data, however, the $2 D$ simulation results are over predicting the experimental data. Further, using three-dimensional SST turbulence model, a very good agreement with the experimental results is found in the work of Plourde et al. [7]. For such reasons, turbulence models $\kappa-\epsilon$ and $\kappa-\omega$ are investigated to identify which model suits best, in comparison with experimental data [14], taking also into account the associated computational efforts. Simulations have been carried out only for statical analyses as the k-omega model was not implemented in Rotating Machinery turbulent physic analysis drawn up on the commercial available software COMSOL Multiphysics ${ }^{\circledR}$. Analyses with structured and unstructured meshes have been performed using both the turbulence models. Number of degrees of freedom (DOF) and computational time for the simulation are reported in Table 1. Simulations with angular displacement $\theta$ from $0^{\circ}$ to $180^{\circ}$ have been conducted in order to compare performances of both models. From Figure 5a, it appears that mesh configurations have no appreciable effects on the static torque coefficient distribution under the $\kappa-\omega$ turbulence model assumption. The same also stands for $\kappa-\epsilon$ model. In Figure 5b results obtained using the unstructured mesh, under the $\kappa-\epsilon$ and the $\kappa-\omega$ models, 
are reported in comparison with experimental data available in literature [14]. It has been obtained that both the $\kappa-\epsilon$ and $\kappa-\omega$ static results are in good accordance with reference data. However, as it stems from Table 1 the computational time needed to solve the unstructured $\kappa-\epsilon$ problem reveals as the lowest and for such reasons this model has been selected to perform the computational characterization of the slotted Savonius wind turbine.

Table 1. Average value for parametric sweep simulation from $0^{\circ}$ to $180^{\circ}$.

\begin{tabular}{ccc}
\hline Configuration & Degree of freedom & Computational time (s) \\
\hline Strcttured $\kappa-\epsilon$ & 213718 & 724 \\
Strcttured $\kappa-\omega$ & 213718 & 807 \\
Unstrcttured $\kappa-\epsilon$ & 161772 & 383 \\
Unstrcttured $\kappa-\omega$ & 161772 & 454 \\
\hline
\end{tabular}

Figure 5. (a) Structured v.s. unstructured mesh; and (b) unstructured $\kappa-\epsilon$ and $\kappa-\omega$ model vs. experimental data [14].

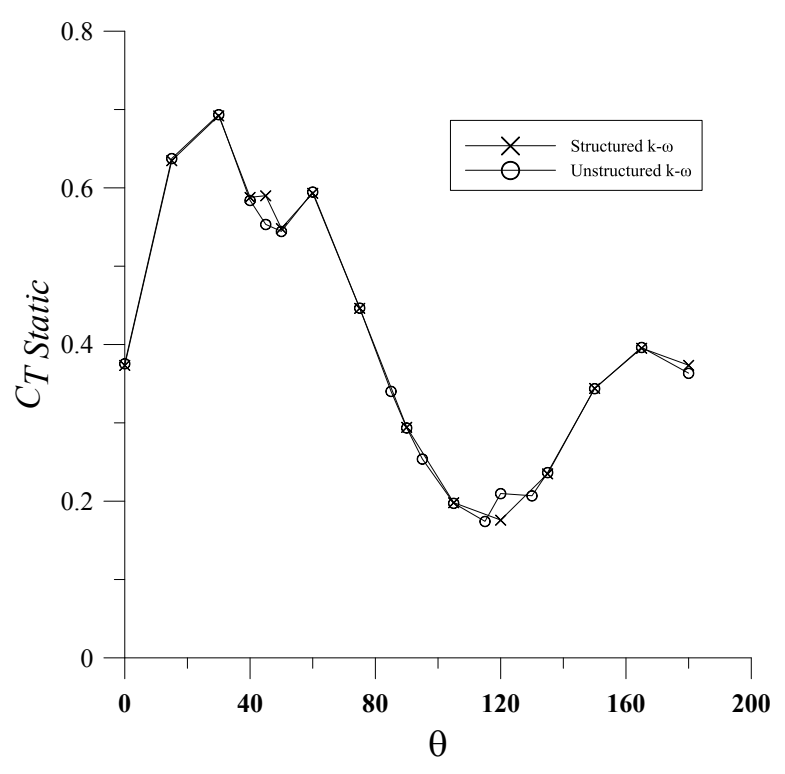

(a)

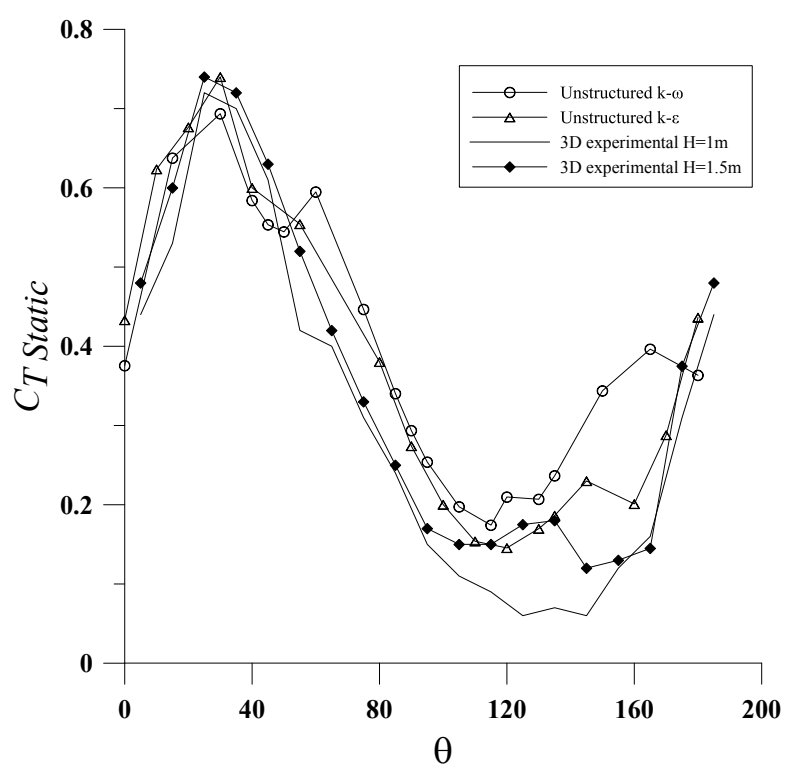

(b)

Moreover it is worth noting that near wall refinement is taken into account. The wall functions in COMSOL Multiphysics ${ }^{\circledR}$ are such that the computational domain is assumed to start a distance $\delta_{w}$ from the wall [18]. The distance $\delta_{w}$ is computed so that:

$$
\delta_{w}^{+}=\rho u_{\tau} \delta_{w} / \mu
$$

where

$$
u_{\tau}=\frac{|\mathbf{u}|}{\frac{1}{\kappa_{v}} \ln \delta_{w}+B}
$$


is the friction velocity. For numerical purpose $\delta_{w}$ should be grater than half of the height of the boundary mesh cell and is determined by the classical law of the wall. For the static analyses the mesh refinement carried out to a value of $\delta_{w}^{+}$equal to 11.06 , whereas for the time-dependent simulation was obtained values between 11.06 and 15.48. In the Equation (11) $\kappa_{v}$ is the von Krman constant, set to 0.41 and B is an empirical constant for smooth walls that is set to 5.2 in accordance with Kuzmin et al. [31].

\section{Results}

Static and transient analyses are carried out in this section to characterize the performances of the investigated wind turbine; its benefits and drawbacks are investigated with respect to the standard. Results are compared with experimental data reported in literature to show the soundness of the employed numerical scheme. Performances of Savonius wind turbine is described in terms of torque and power coefficients, $C_{T}$ and $C_{P}$ respectively, which are computed using procedures described in $[12,14,16]$. On the other hand, dynamical wind turbine performances are obtained by computing the average of both torque and power coefficients, $C_{T}^{A v}$ and $C_{P}^{A v}$ respectively, over an operational cycle of the rotor.

\subsection{Validation Results}

The averaged torque coefficients are computed for different tip speed ratio and the results compared to experimental [14]. As it can be observed from Figure 6, very good agreement is achieved for all tip speed ratio $\lambda$ validating the numerical scheme employed to analyze the proposed Savonius turbine configuration. Being $\lambda$ equals to $U / V$, where $\mathrm{U}$ is the tip peripheral velocity of the rotor equal to $\omega R$, $\omega$ is the angular velocity of the blade and $R$ is the rotor radius while $V$ is the free stream velocity which has been kept constant to $7 \mathrm{~m} / \mathrm{s}$.

Figure 6. Averaged $C_{T}^{A v}$ coefficients for CFD model vs. experimental data [14].

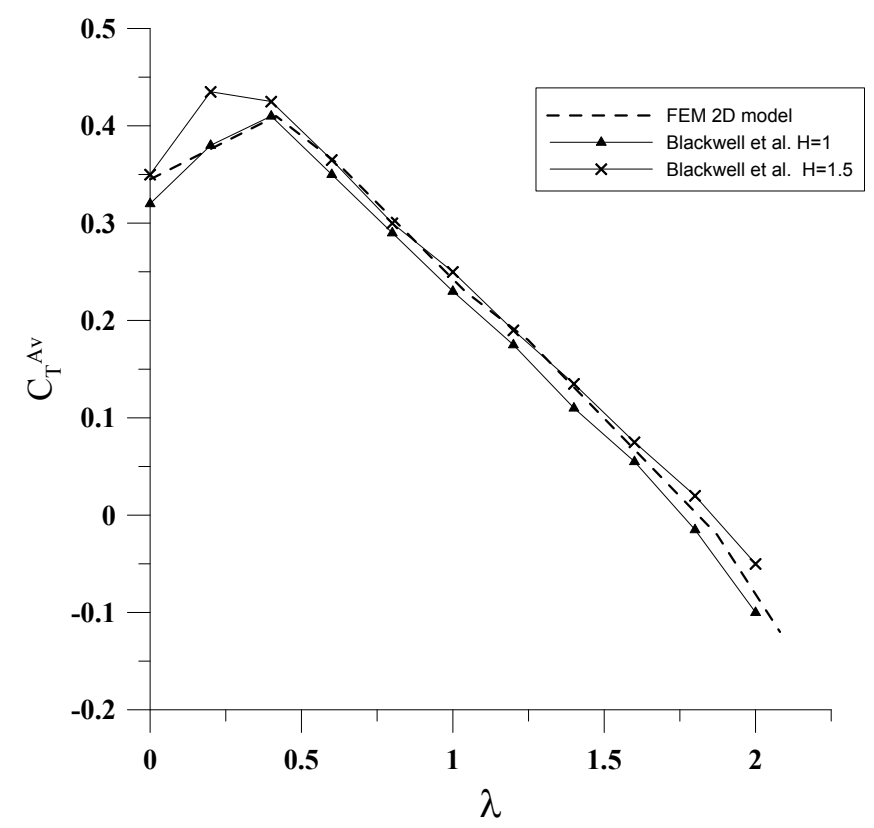


Two dimensional simulation led to a slight overprediction of the static torque compared to the real three dimensional with endplate rotor experiments for angular values of $\theta$ between $70^{\circ}$ and $100^{\circ}$ as demonstrated in Figure 5b.

\subsection{Results for the Slotted Blades}

The first analysis is performed with the aim to study the effect on turbine starting performances (i.e., static analysis) by varying slot position $\mathrm{f}$ and keeping constant the "slot gap". More particularly, slot position $\mathrm{f}$ is defined in percentage of blade chord line and static analyses are performed by varying the rotor angular position from $0^{\circ}$ to $180^{\circ}$. From the obtained results, shown in Figure 7 , it can be inferred that the presence of the slot for position $\mathrm{f}$ lower than $40 \%$ improves the starting torque performance of the turbine with respect to the standard configuration.

Figure 7. Torque static coefficients for standard (a) $f=1 \%, f=3 \%$ and $f=12 \%$; and for (b) $f=25 \%, f=40 \%, f=60 \%$ and $f=75 \%$.

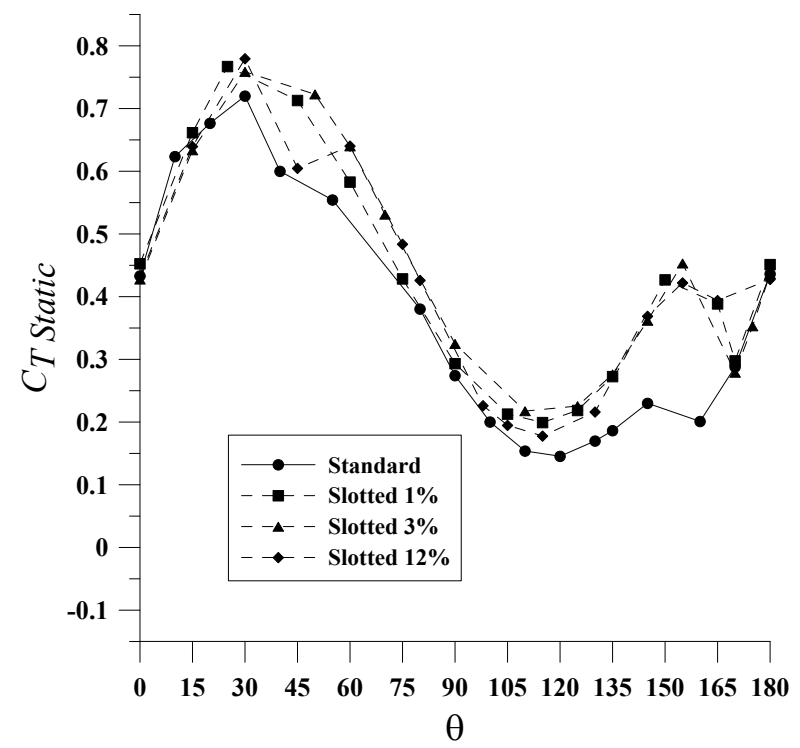

(a)

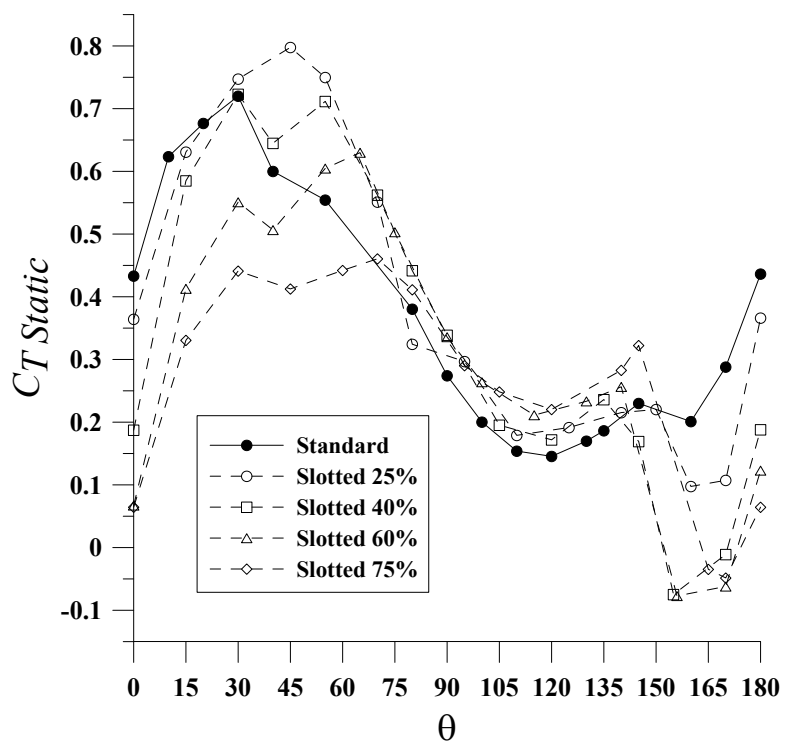

(b)

The same trend is confirmed by values of static average torque coefficient, $C_{T}$ Static, computed over half a cycle and listed in Table 2, where it is also evidenced that best configurations are those corresponding to $f=1 \%, f=3 \%$ and $f=12 \%$.

Table 2. Average $C_{T}$ Static value over half a cycle of the rotor.

\begin{tabular}{cccc}
\hline Configuration & $\mathbf{C}_{\mathrm{T}}$ Static & Configuration & $\mathbf{C}_{\mathrm{T}}$ Static \\
\hline Standard & 0.345 & $\boldsymbol{f}=\mathbf{2 5} \%$ & 0.389 \\
$\boldsymbol{f}=\mathbf{1} \%$ & 0.425 & $\boldsymbol{f}=\mathbf{4 0} \%$ & 0.338 \\
$\boldsymbol{f}=\mathbf{3} \%$ & 0.442 & $\boldsymbol{f}=\mathbf{6 0} \%$ & 0.304 \\
$\boldsymbol{f}=\mathbf{1 2} \%$ & 0.428 & $\boldsymbol{f}=\mathbf{7 5} \%$ & 0.260 \\
\hline
\end{tabular}


The second set of analyses deal with the dynamic behavior of Savonius generator obtained for the same slot configurations analyzed for static conditions. The dynamic response is characterized in terms of dynamic average torque and power coefficients, $C_{T}^{A v}$ and $C_{P}^{A v}$ respectively, by varying the tip speed ratio $\lambda$. From the results reported in Figures 8 and 9 it appears that the best configuration is the one represented by a slot position corresponding to $f=1 \%$. It must be noticed that, for given free stream velocity, the torque coefficient and the power coefficient grow with omega in standard configuration, until the best operating condition $\lambda=1$ are met.

Figure 8. Averaged $C_{T}^{A v}$ coefficients for standard (a) $f=1 \%, f=3 \%$ and $f=12 \%$; and for (b) $f=25 \%, f=40 \%, f=60 \%$ and $f=75 \%$.

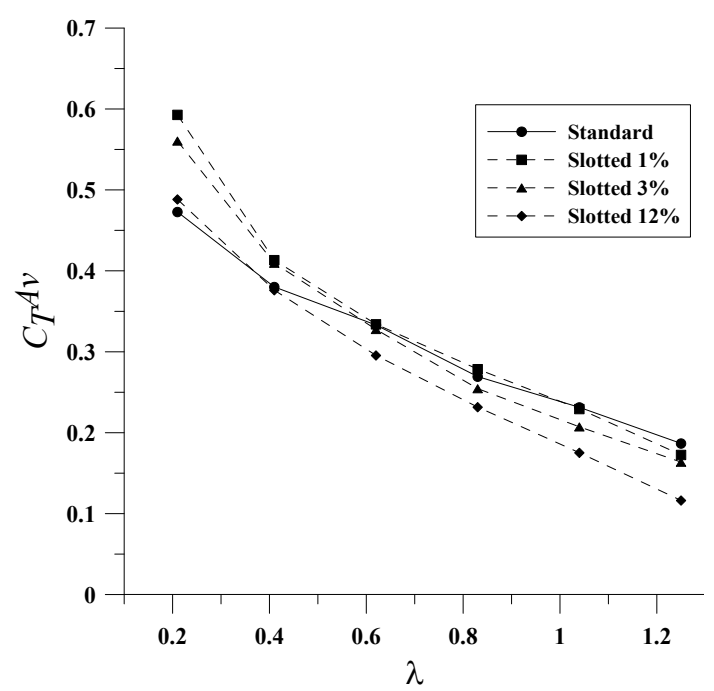

(a)

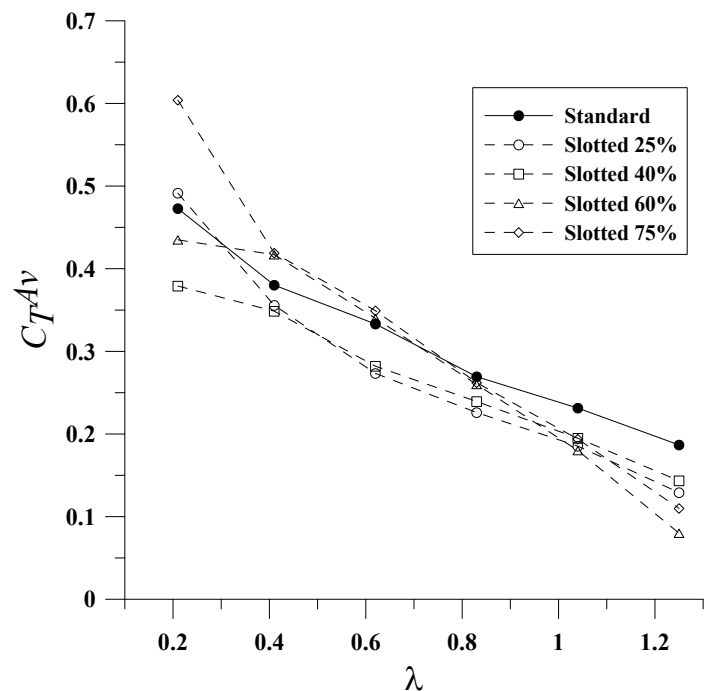

(b)

Figure 9. Averaged $C_{P}^{A v}$ coefficients for standard (a) $f=1 \%, f=3 \%$ and $f=12 \%$; and for (b) $f=25 \%, f=40 \%, f=60 \%$ and $f=75 \%$.

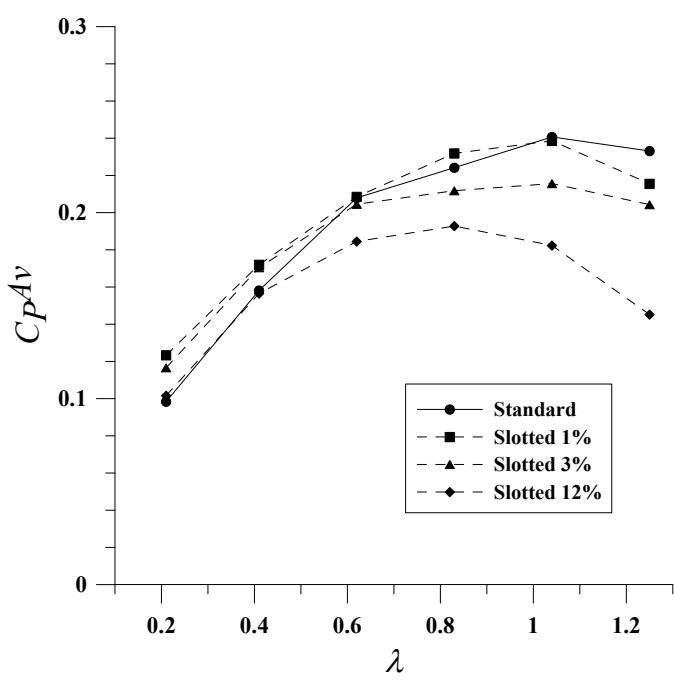

(a)

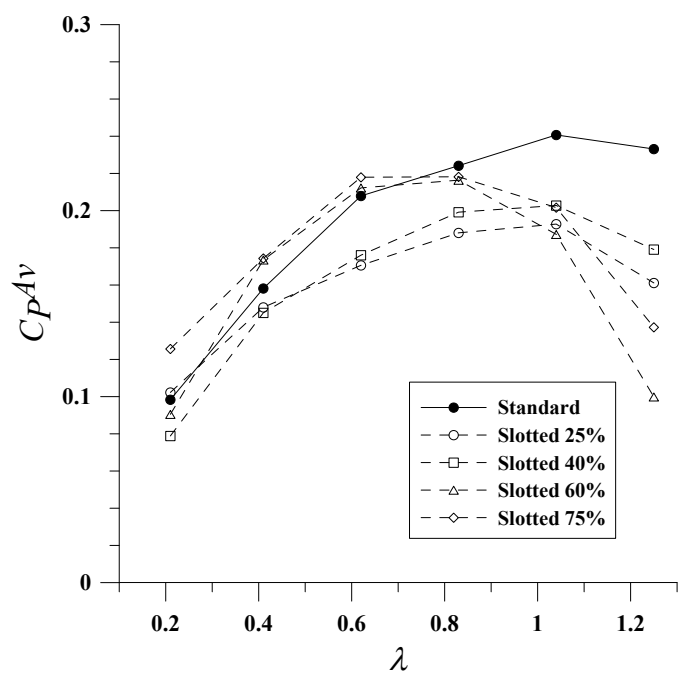

(b) 
Moreover, it is possible to highlight that for low tip speed ratio $\lambda$, all of the slotted configurations are characterized by better torque and power performances with respect to the standard one with the only exception of slotted configuration having $f \geqq 60 \%$. On the other hand, for higher values of the tip speed ratio $\lambda$, the presence of the slot leads to a deterioration of blade performances with respect to the standard configuration.

In order to fully characterize the behavior of the Savonius turbine, the instantaneous torque coefficient is plotted in Figure 10 for different slotted configurations with respect to the standard one. It is worth noting that highest peaks of the torque coefficient values are obtained for high values of $f$, which is representative of a slot position moving towards the leading edge of blades.

Figure 10. Dynamic torque coefficient vs blade angular position $\theta$ at $\lambda=1$ for standard (a) $f=1 \%, f=3 \%$ and $f=12 \%$; and for (b) $f=25 \%, f=40 \%, f=60 \%$ and $f=75 \%$.

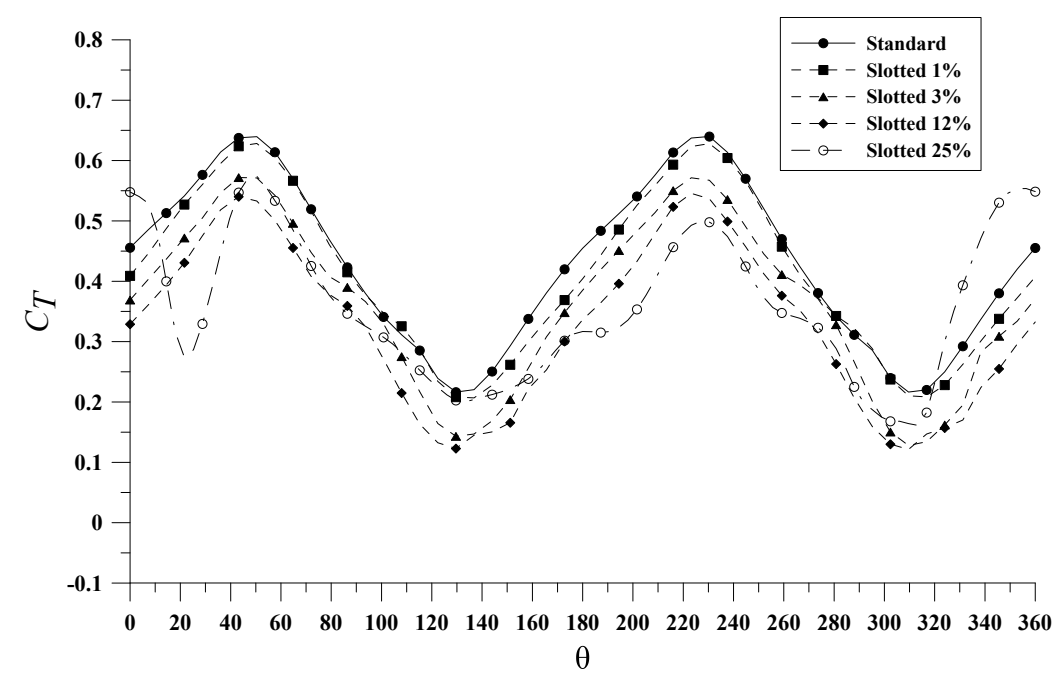

(a)

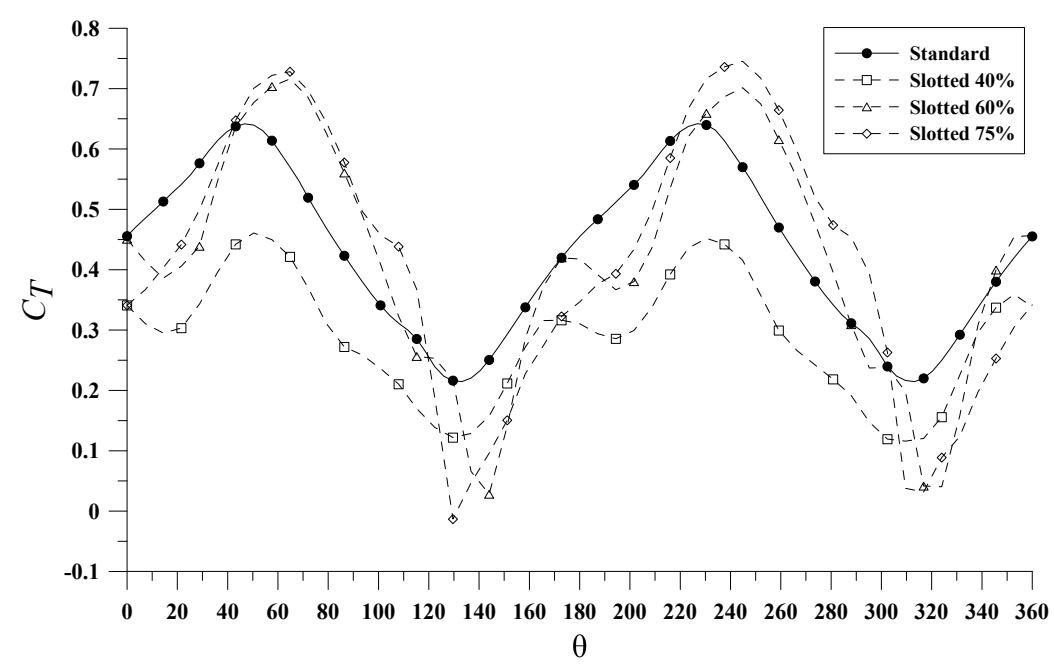

(b)

For slotted configurations $f=60 \%$ and $f=75 \%$ in the range through $40^{\circ}$ and $120^{\circ} \theta$ values, the blowing of the fluid from the bottom to the top side of the blade allows to delay the separation 
of the main vortical region close to the leading edge of the blade moving in forward direction, thus improving aerodynamic performances of blades, in addition the drag of the returning blade is reduced by the presence of the "slot gap".

This behavior is highlighted for a particular case, $f=75 \% \theta=248.4^{\circ}$, by the gauge pressure distribution, equal to absolute pressure minus atmospheric pressure, shown in Figure 11 and by the velocity contours shown in Figure 12. All the contours are referred to the angular position where maximum value of the torque coefficient are reached, see Figure 10.

Figure 11. Gauge pressure distribution $[\mathrm{Pa}]$ for the standard (a) and $f=75 \%$; (b) configurations at $\lambda=1$.

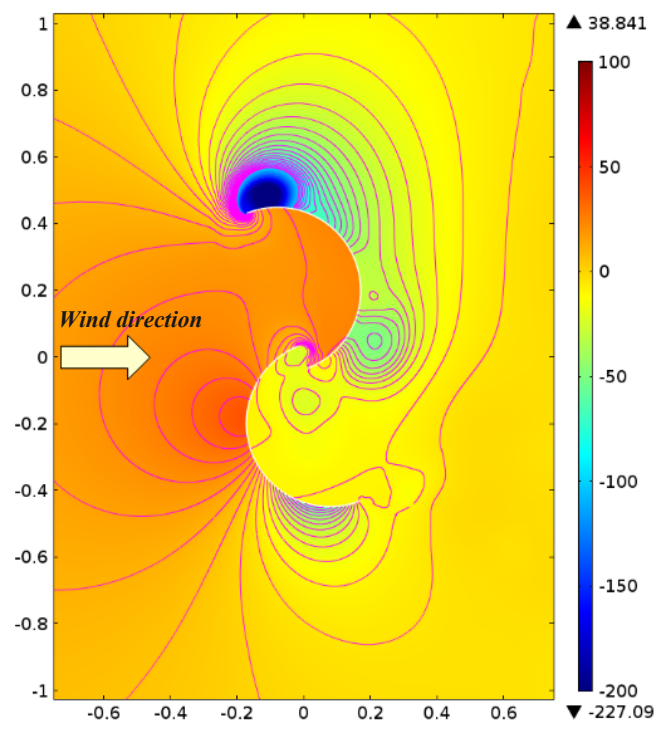

(a)

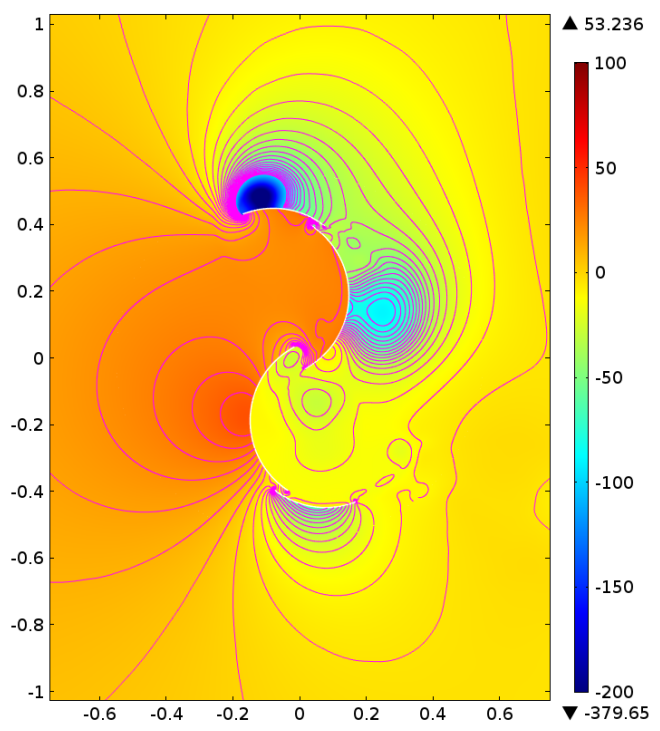

(b)

Figure 12. Velocity vector contours for the standard (a) and $f=75 \%$; (b) analyzed at $\lambda=1$.

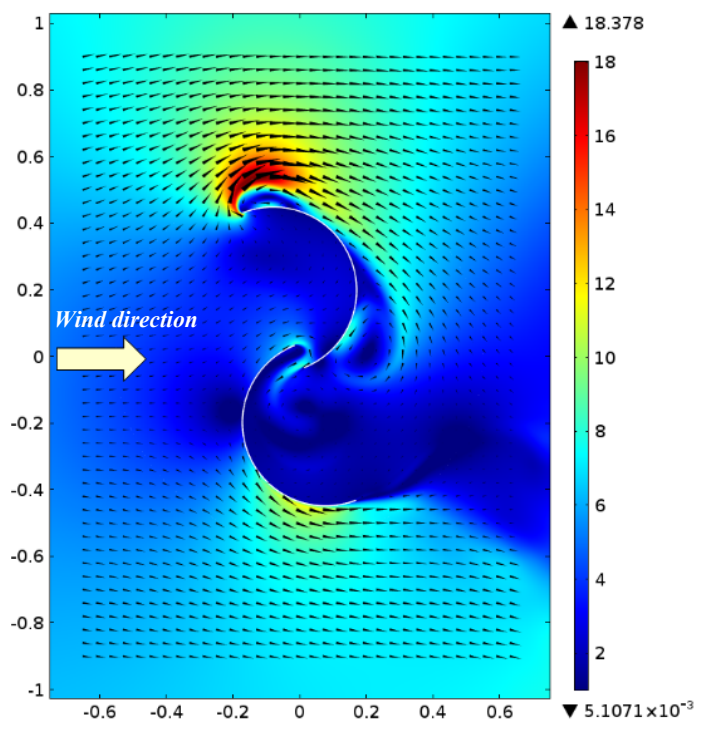

(a)

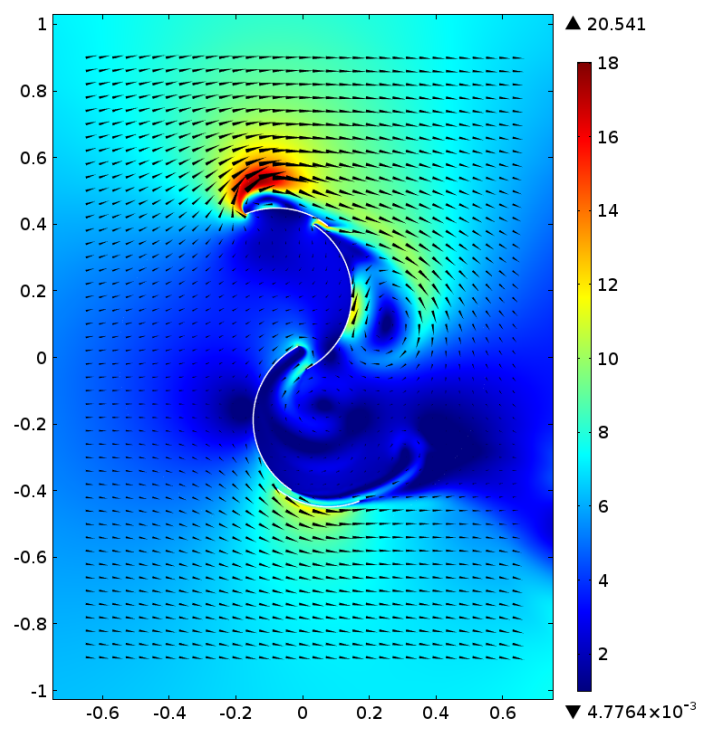

(b) 
Moreover, Figure 11 shows how the presence of slot increase the pressure difference through the upperwind and lowerwind zones; in fact, for the advancing blade the slat near the leading edge increase the external velocity as shown in Figure 12 producing a major rotating torque generated by the lift effect, furthermore the lowerwind central zone reveal an underpressure region more extended which also contribute to increase the torque.

For the sake of completeness and to better highlight the trend of the torque coefficient over a full cycle, the polar distributions of two different representative tip speed ratio $\lambda=0.4$ and $\lambda=1.25$ are shown in Figures 13 and 14 respectively.

Figure 13. Polar torque coefficient distribution at $\lambda=0.4$.

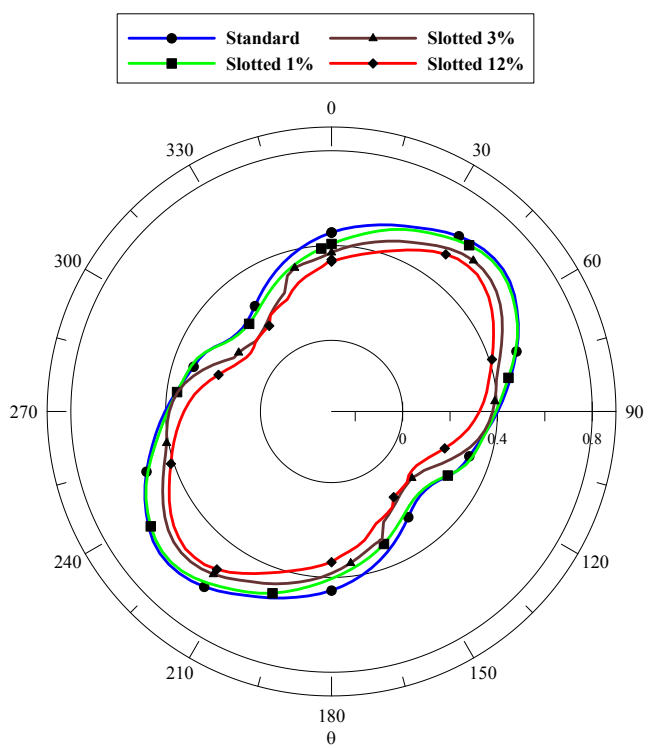

(a)

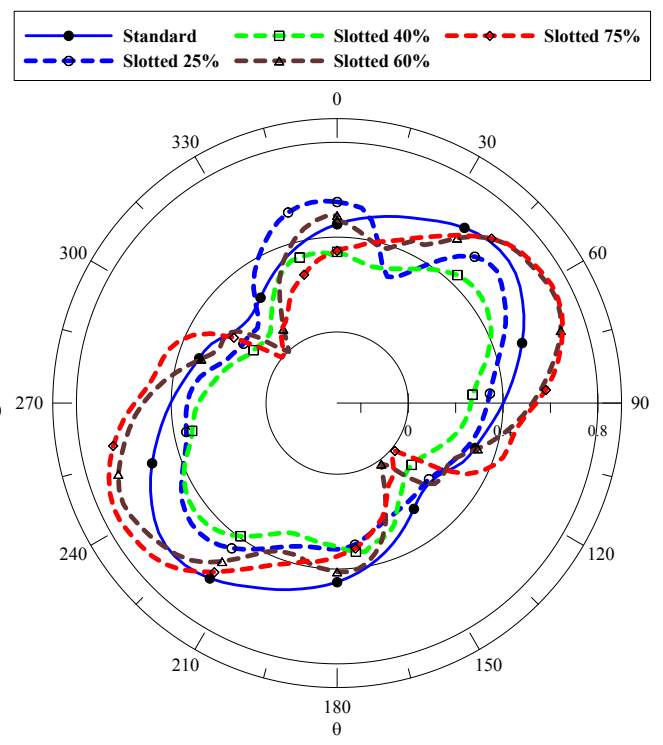

(b)

Figure 14. Polar torque coefficient distribution at $\lambda=1.25$.

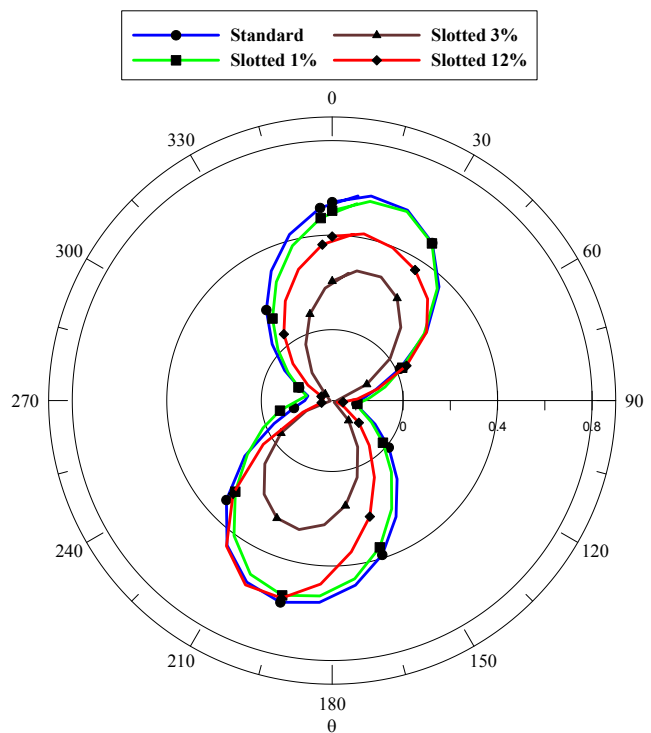

(a)

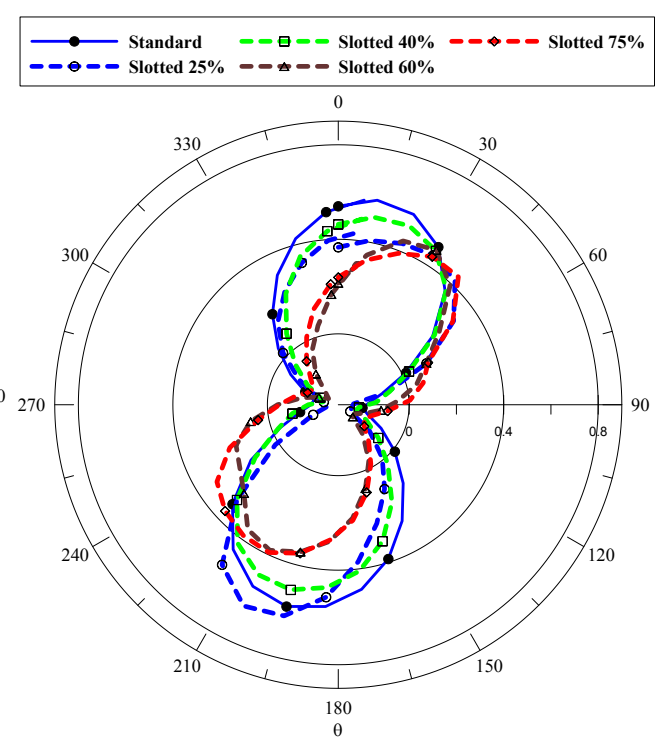

(b) 
Figure 13 show that all of the configurations provide similar torque variations except for configuration having $f \geqq 40 \%$. For high values of TSR as shown in Figure 14 no fluctuation appear but average torque value decrease drastically, in particular for $f=3 \%$ configuration.

The last set of analyses aim at showing the effect of the slot angle $\beta$, see Figure 15. Slot position corresponding to $f=1 \%$, is considered as it shows the best averaged torque performances. Results are shown in Figure 16 in terms of averaged torque and averaged power coefficients by varying the tip speed ratio $\lambda$. It is possible to point out that, as already mentioned, presence of the slot leads to an improvement of blade performances with respect to the standard configuration at low rotational speed but the effects of the slot angle variation can be considered negligible.

Figure 15. Savonius geometry with slot angle " $\beta$ " definition.

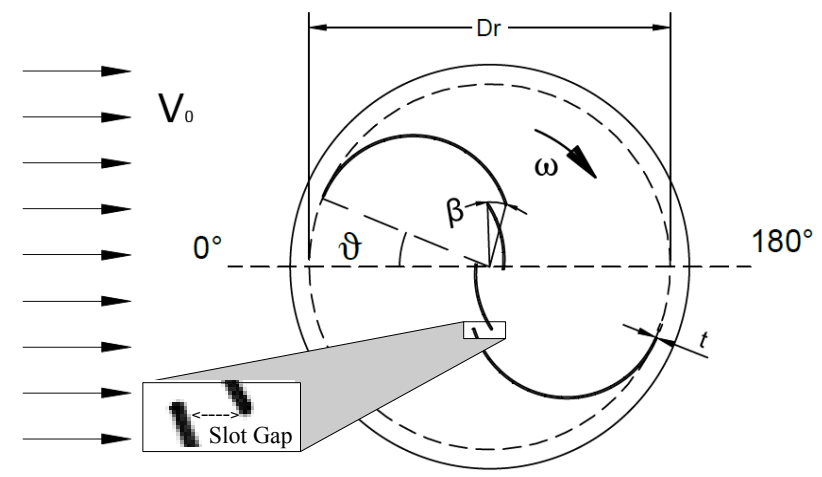

Figure 16. (a) Averaged $C_{T}^{A v}$; and (b) $C_{P}^{A v}$ coefficients for $f=1 \%$ and different angle $\beta$.

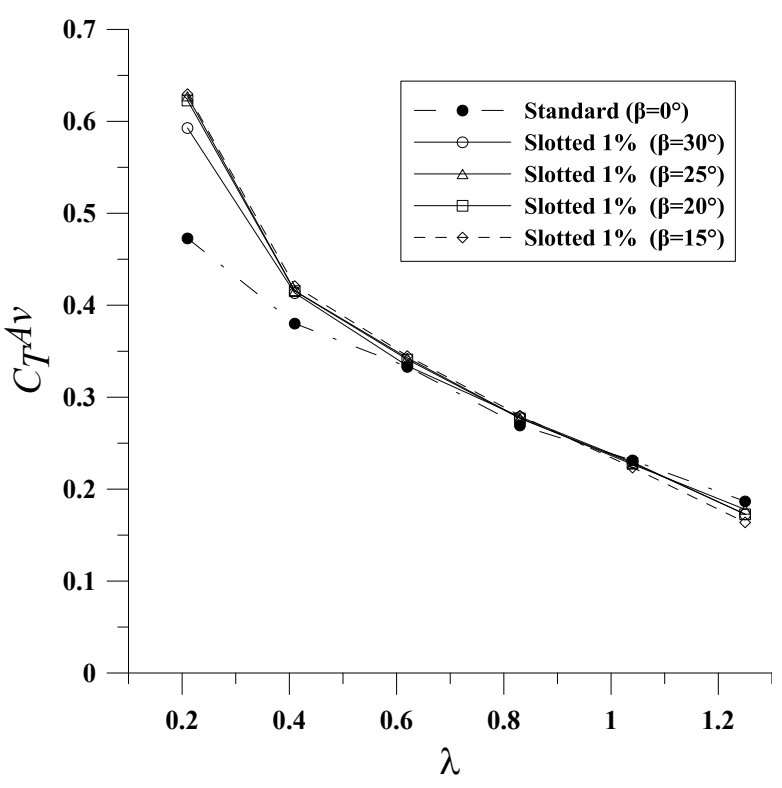

(a)

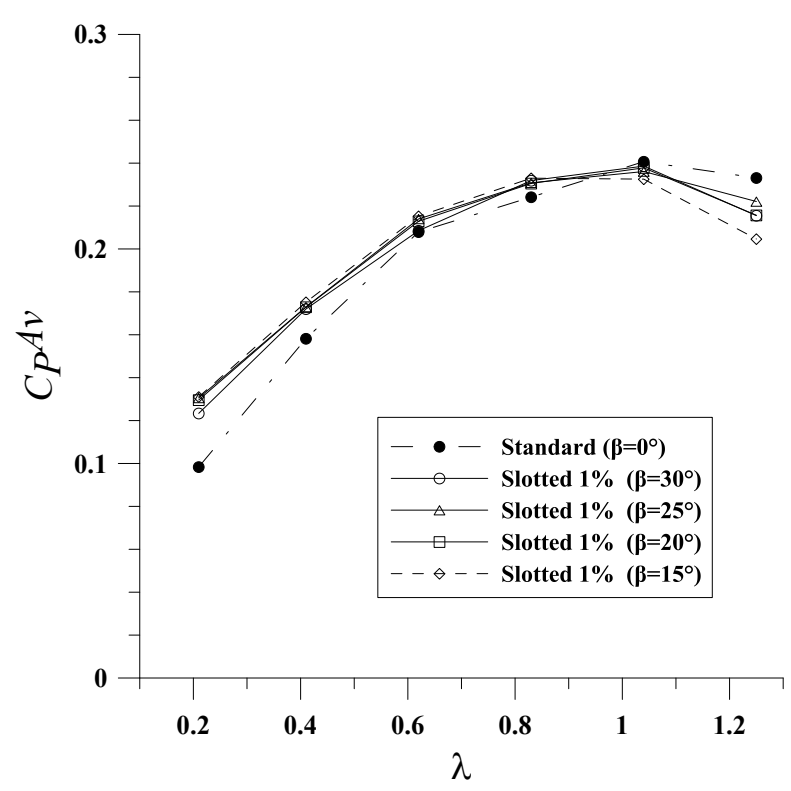

(b)

\section{Conclusions}

A new bucket configuration for Savonius wind turbine has been presented in this work. Slotted savonius blades have been considered and then compared to classical configuration considering blades 
overlap only. Numerical simulations have been carried out by means of the commercial code COMSOL Multiphysics ${ }^{\circledR}$. The static analyses have pointed out better starting torque performances of the slotted blades with respect to the standard configuration for slot position $\mathrm{f}$ less than $40 \%$. Moreover, under dynamic conditions, the obtained results have shown that this new configuration performs better than the Standard one only at low angular velocity. Lastly, the configuration characterized by $f=1 \%$, which has shown the better aerodynamic performances, have been analyzed by varying the slot angle $\beta$. The obtained results have shown very small influence of the slot angle $\beta$ on the torque and power coefficients.

\section{Acknowledgments}

The authors would like to acknowledge the "Programma Operativo Regionale FESR Sicilia 2007-2013 Asse IV, Obiettivo Operativo 4.1.1, Linea di intervento 4.1.1.2", for financing the research proposed in the present paper. The paper was in fact developed in the framework of the research project “G.RE.EN.-UPGRADED RENEWABLE ENERGY SYSTEM, CUP:G23F12000000004”, founded by PO-FESR Sicilia 2007-2013.

\section{References}

1. World Energy Outlook Edition; IEA Publications: Paris, France, 2012; p. 690.

2. Messineo, A.; Marchese, F. Performance evaluation of hybrid RO/MEE systems powered by a WTE plant. Desalination 2008, 229, 82-93.

3. Asdrubali, F.; Cotana, F.; Messineo, A. On the evaluation of solar greenhouse efficiency in building simulation during the heating period. Energies 2012, 5, 1864-1880.

4. Messineo, A.; Panno, D. Potential applications using LNG cold energy in Sicily. Int. J. Energy Res. 2008, 32, 1058-1064.

5. Muller, G.; Jentsch, M.F.; Stoddart, E. Vertical axis resistance type wind turbines for use in buildings. Renew. Energy 2009, 34, 1407-1412.

6. Burton, T.; Sharpe, D.; Jenkins, N.; Bossanyi, E. Wind-Turbine Performance. In Wind Energy Handbook; John Wiley \& Sons Ltd.: Chichester, UK, 2002; pp. 173-207.

7. Plourde, B.D.; Abraham, J.P.; Mowry, G.S.; Minkowycz, W.J. Simulations of three-dimensional vertical-axis turbines for communications applications. Wind Eng. 2012, 36, 443-454.

8. Abraham, J.P.; Mowry, G.S.; Plourde, B.P.; Sparrow, E.M.; Minkowycz, W.J. Numerical simulation of fluid flow around a vertical-axis turbine. J. Renew. Sustain. Energy 2011, 3, 033109:1-033109:13. doi:10.10631.3588037.

9. Saha, U.; Thotla, S.; Maity, D. Optimum design configuration of Savonius rotor through wind tunnel experiments. J. Wind Eng. Ind. Aerodyn. 2008, 96, 1359-1375.

10. Gupta, R.; Biswas, A.; Sharma, K. Comparative study of a three-bucket Savonius rotor with a combined three-bucket Savonius-three-bladed Darrieus rotor. Renew. Energy 2008, 33, 1974-1981.

11. Altan, B.D.; Atilgan, M. An experimental and numerical study on the improvement of the performance of Savonius wind rotor. Energy Convers. Manag. 2008, 49, 3425-3432. 
12. Fujisawa, N. Velocity measurements and numerical calculations of flow fields in and around Savonius rotors. J. Wind Eng. Ind. Aerodyn. 1996, 59, 39-50.

13. Akwa, J.V.; da Silva Júnior, G.A.; Petry, A.P. Discussion on the verification of the overlap ratio influence on performance coefficients of a Savonius wind rotor using computational fluid dynamics. Renew. Energy 2012, 38, 141-149.

14. Sheldahl, R.E.; Feltz, L.V.; Blackwell, B.F. Wind tunnel performance data for two- and three-bucket Savonius rotors. J. Energy 1978, 2, 160-164.

15. Savonius, S.J. The S-rotor and its applications. Mech. Eng. 1931, 53, 333-338.

16. Alaimo, A.; Milazzo, A.; Trentacosti, F.; Esposito, A. On the effect of slotted blades on savonius wind generator performances by CFD analysis. Adv. Mater. Res. 2012, 512-515, 747-753.

17. COMSOL Inc. CFD Module User's Guide; COMSOL: Palo Alto, CA, USA, 2013.

18. COMSOL Inc. COMSOL Multiphysics Reference Manual; COMSOL: Palo Alto, CA, USA, 2013.

19. Greenspan, H. The Theory of Rotating Fluids; Cambridge Monographs On Mechanics and Applied Mathematics, Breukelen Press: Brookline, MA, USA, 1990.

20. Batchelor, G. An Introduction to Fluid Dynamics; Cambridge Mathematical Library, Cambridge University Press: Cambridge, UK, 2000.

21. Donea, J.; Huerta, A.; Ponthot, J.P.; Rodríguez-Ferran, A. Arbitrary Lagrangian-Eulerian Methods. In Encyclopedia of Computational Mechanics; John Wiley \& Sons Ltd.: Chichester, UK, 2004.

22. Wilcox, D.C. Turbulence Modeling for CFD; DCW Industries La Canada: La Canada, CA, USA, 1998; Volume 2.

23. Launder, B.; Spalding, D. Lectures in Mathematical Models of Turbulence; Academic Press: Philadelphia, PA, USA, 1972.

24. Deuflhard, P. A modified Newton method for the solution of ill-conditioned systems of nonlinear equations with application to multiple shooting. Numer. Math. 1974, 22, 289-315.

25. Hindmarsh, A.C.; Brown, P.N.; Grant, K.E.; Lee, S.L.; Serban, R.; Shumaker, D.E.; Woodward, C.S. SUNDIALS: Suite of nonlinear and differential/algebraic equation solvers. ACM Trans. Math. Softw. 2005, 31, 363-396.

26. Spalart, P.R.; Allmaras, S.R. A one equation turbulence model for aerodinamic flows. AIAA J. 1992, 94, doi:10.2514/6.1992-439.

27. Pope, K.; Rodrigues, V.; Doyle, R.; Tsopelas, A.; Gravelsins, R.; Naterer, G.; Tsang, E. Effects of stator vanes on power coefficients of a zephyr vertical axis wind turbine. Renew. Energy $\mathbf{2 0 1 0}$, $35,1043-1051$.

28. Howell, R.; Qin, N.; Edwards, J.; Durrani, N. Wind tunnel and numerical study of a small vertical axis wind turbine. Renew. Energy 2010, 35, 412-422.

29. Kamoji, M.; Kedare, S.; Prabhu, S. Performance tests on helical Savonius rotors. Renew. Energy 2009, 34, 521-529.

30. Menter, F.R. Two-equation eddy-viscosity turbulence models for engineering application. AIAA J. 1994, 32, 1598-1605. 
31. Kuzmin, D.; Mierka, O.; Turek, S. On the Implementation of the k-Epsilon Turbulence Model in Incompressible Flow Solvers Based on a Finite Element Discretization; Ergebnisberichte des Instituts für Angewandte Mathematik, Nummer 345; Technical Report for Fakultät für Mathematik, TU Dortmund: Dortmund, Germany, 2007;

(c) 2013 by the authors; licensee MDPI, Basel, Switzerland. This article is an open access article distributed under the terms and conditions of the Creative Commons Attribution license (http://creativecommons.org/licenses/by/3.0/). 